\title{
Structure and Function of the Hair Cell Ribbon Synapse
}

\author{
R. Nouvian ${ }^{1}$, D. Beutner ${ }^{1}$, T.D. Parsons ${ }^{2}$, T. Moser $^{1}$ \\ ${ }^{1}$ InnerEarLab, Department of Otolaryngology, Goettingen University Medical School, and Center for Molecular Physiology of the Brain, \\ Robert-Koch-Strasse 40, 37075 Goettingen, Germany \\ ${ }^{2}$ Clinical Studies-New Bolton Center, School of Veterinary Medicine and Otorhinolaryngology-Head and Neck Surgery, School of \\ Medicine, University of Pennsylvania, Philadelphia, PA 19104, USA
}

Received: 3 February 2006

\begin{abstract}
Faithful information transfer at the hair cell afferent synapse requires synaptic transmission to be both reliable and temporally precise. The release of neurotransmitter must exhibit both rapid on and off kinetics to accurately follow acoustic stimuli with a periodicity of $1 \mathrm{~ms}$ or less. To ensure such remarkable temporal fidelity, the cochlear hair cell afferent synapse undoubtedly relies on unique cellular and molecular specializations. While the electron microscopy hallmark of the hair cell afferent synapse - the electron-dense synaptic ribbon or synaptic body - has been recognized for decades, dissection of the synapse's molecular make-up has only just begun. Recent cell physiology studies have added important insights into the synaptic mechanisms underlying fidelity and reliability of sound coding. The presence of the synaptic ribbon links afferent synapses of cochlear and vestibular hair cells to photoreceptors and bipolar neurons of the retina. This review focuses on major advances in understanding the hair cell afferent synapse molecular anatomy and function that have been achieved during the past years.
\end{abstract}

Key words: Hair cell - Ribbon synapse - Exocytosis - Synaptic vesicle pool - Synaptic ribbon Hair cell - Calcium - Synaptic protein

\section{Introduction}

Hearing relies on faithful synaptic transmission at the ribbon synapse of auditory hair cells. Figure 1 shows

Present address for D. B.: Department of Otorhinolaryngology, Head and Neck Surgery, University of Cologne Medical School, Kerpener Straße 62, 50924 Koeln, Germany

Correspondence to: T. Moser; email: tmoser@gwdg.de an electron micrograph of a typical hair cell ribbon synapse. The synapse is characterized by the presence of a large presynaptic organelle, the synaptic ribbon or dense body, that tethers synaptic vesicles and is itself anchored to the active zone. The performance of this synapse is remarkable in several aspects.

\section{Phasic Release Properties}

The synapse's precision to code the temporal fine structure of acoustic stimuli is unparalleled. For example, our capacity to locate sound sources in space depends on interaural time differences in the arrival of sound of only tens to hundreds of microseconds. Unlike a conventional synapse that is driven by action potentials, the hair cell afferent synapse responds to graded changes in membrane potential. While the action potential results in a strong all-or-none stimulus-secretion coupling, the hair cell afferent synapse is faced with the challenge of encoding sounds of extremely different intensities and, hence, must rely on mechanisms that allow for variable stimulus-secretion coupling. At the same time, the hair cell afferent synapse must also maintain temporal fidelity. For example, the firing of an auditory nerve fiber can follow at a constant phase relationship the periodicity of tonal stimuli into the low $\mathrm{kHz}$ range of frequencies, and we infer that the hair cell neurotransmitter release must comply with this extraordinary timing. Such temporal precision in synaptic transmission is even observed with sub-threshold stimuli, where the temporal pattern of spike firing regularizes already before there is an overall increase in the discharge rate.

\section{Tonic Release Properties}

As we all can tell from our own experience, the cochlear hair cell afferent synapse must be able to 


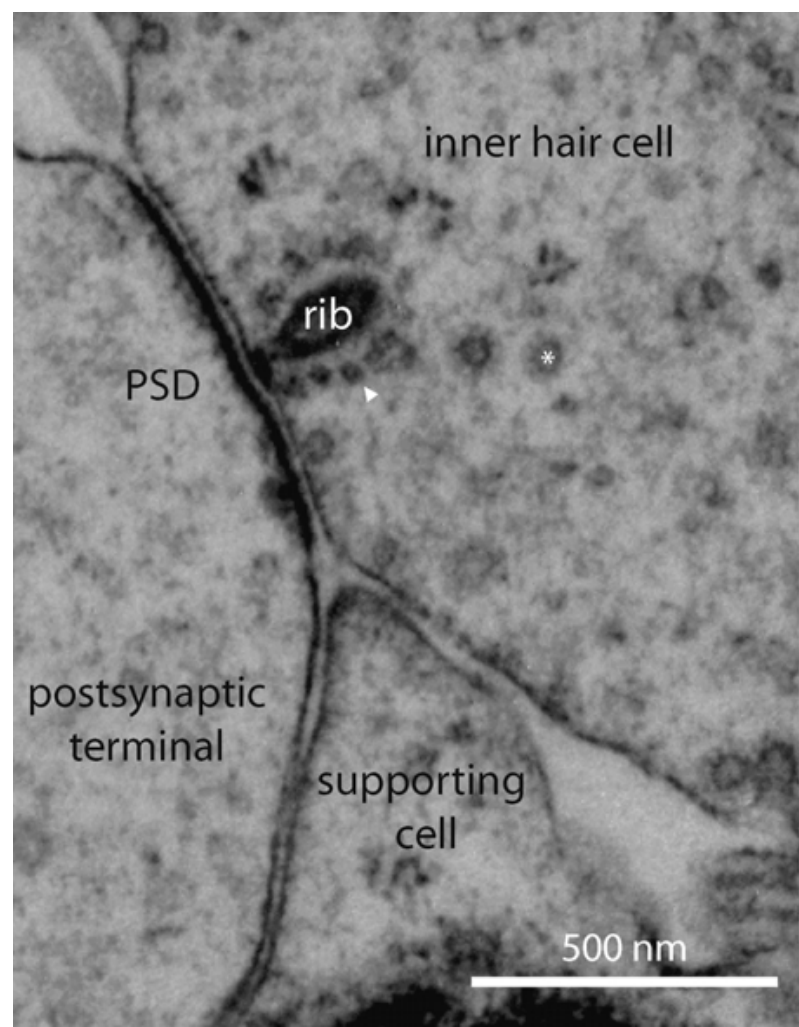

Fig. 1. Hair cell ribbon synapse. Electron micrograph of an inner hair cell afferent synapse of an 8-week-old mouse. The ribbon (rib) is anchored to the presynaptic plasma membrane and faces the postsynaptic density $(P S D)$ of the auditory nerve fibers. The arrowhead and the star indicate a ribbon-associated synaptic vesicle and a free cytoplasmic coated vesicle, respectively.

encode prolonged, ever-present sounds. For example, despite adaptation, the constant background noise of the room's air handling system is faithfully reported by the peripheral auditory system. To meet this requirement of audition, sustained neurotransmitter release must be maintained and implicates the need for extensive synaptic vesicle cycling (both, vesicle exo- and endocytosis). The hair cell afferent synapse's capacity for sustained signal has often been attributed to the presence of the synaptic ribbon, and apparent depot of synaptic vesicles. However, recent morphological and physiological studies suggest additional/ different roles for the hair cell synaptic ribbon, and have fuelled the structure-function debate at the ribbon synapse.

\section{Molecular Anatomy and Physiology of the Hair Cell Synapse}

We are still far from a comprehensive understanding of the molecular composition of the presynaptic active zone and the postsynaptic density of the hair cell afferent synapse. Homologies between retinal and inner ear sensory ribbon-type active zones are evident (Safieddine \& Wenthold, 1999). Given the larger number of receptor cells in the retina (millions of photoreceptors vs. thousands of coding hair cells) and relative accessibility of the visual end organ, a more advanced molecular description is available presently for retinal ribbon synapses (e.g., tom Dieck et al., 2005) and promises to guide our understanding of auditory and vestibular ribbon synapses. For example, ribbons in both organs contain RIBEYE (Schmitz, Konigstorfer \& Sudhof, 2000; Zenisek et al., 2003; Khimich et al., 2005), Bassoon and Piccolo (Khimich et al., 2005; tom Dieck et al., 2005). RIBEYE is thought to be a structural component of the ribbon but may also have enzymatic activity at the synapse (Schmitz et al., 2000). The photoreceptor ribbon also contains the close RIBEYE homologue and transcriptional co-repressor C-terminal binding protein 1 (tom Dieck et al., 2005). A putative role for this enzyme's lysophosphatidic acid acyl-CoA transferase activity in membrane fission has been proposed (Valente et al., 2005, but see for an opposing view Gallop, Butler \& McMahon, 2005). Some hint for a ribbon function in membrane fission may be seen in the accumulation of cisternal membrane profiles in ribbon-deficient inner hair cells (IHCs) (Khimich et al., 2005). However, any hypothesized enzymatic role for this ribbon constituent in synaptic transmission will require further investigation.

Bassoon, like Piccolo, is a large cytomatrix molecule found at the active zone, and most likely contributes to the anchoring of the ribbon at the active zone (Dick et al., 2001; Dick et al., 2003; Khimich et al., 2005). Deletion of a major part of the Bassoon gene (Altrock et al., 2003) results in the lack of synapse-anchored ribbons at most active zones of mouse IHCs. Moreover, the amplitude of a readily releasable pool of IHC synaptic vesicles is decreased, and both synchronous afferent synaptic transmission and hearing are impaired (Khimich et al., 2005). In addition, a minor reduction in the $\mathrm{IHC} \mathrm{Ca}^{2+}$ current is observed, potentially reflecting impaired insertion of $\mathrm{Ca}^{2+}$ channels at the active zone due to the Bassoon and/or ribbon deficiency. Although less severe than the complete synaptic dysfunction resulting from the lack of $\mathrm{Ca}_{\mathrm{v}} 1.3$ channels (Brandt, Striessnig \& Moser, 2003), the loss of ribbons causes a synaptopathic hearing impairment with the previously described audiological signature of an auditory neuropathy (preserved cochlear amplification but impaired auditory evoked potentials). Interestingly, hearing was found intact in a Piccolo mutant (Sendin and Moser, unpublished data), but some immumoactivity was observed in the Synapses of the mutants. Perhaps the failure of the Piccolo mutation to impair hearing reflects a sufficient abundance of residual functional Piccolo protein in the mutant mouse or the action of some unknown compensatory mechanism. 
Hair cells express the SNARE proteins syntaxin 1, SNAP-25 and synaptobrevin 1 (Safieddine \& Wenthold, 1999). These proteins are thought to build the key exocytic machinery, as their cleavage by clostridial neurotoxins shuts off exocytosis in other systems (e.g., Xu et al., 1998; Sakaba et al., 2005). The effects of clostridial neurotoxin action on hair cell afferent synaptic transmission remain to be investigated. Hair cell afferent synapses, like photoreceptor synapses, lack synapsins (Favre et al., 1986; Safieddine \& Wenthold, 1999), a class of proteins that are involved in synaptic vesicle mobilization. Moreover, synaptotagmins 1 and 2, which are considered the calcium sensors of vesicle fusion in the central nervous system and neuroendocrine cells (Sudhof, 2004), have not been observed in hair cells (Safieddine \& Wenthold, 1999). Genetic ablation of Synaptotagmin 7 in mice, which is expressed in IHCs (Safieddine \& Wenthold, 1999) and involved in exocytosis of hippocampal neurons (Virmani et al., 2003), did not result in a hearing impairment (Nouvian and Moser, unpublished data). Thus, taken together, these findings suggest that either other synaptotagmin isoforms or other proteins altogether may act as the calcium sensor at the hair cell afferent synapse.

Despite some homologies, IHC ribbon synapses differ molecularly from retinal ribbon synapses. Most prominently, IHC transmitter release and sound coding are controlled by $\mathrm{Ca}_{\mathrm{V}} 1.3 \mathrm{Ca}^{2+}$ channels (Platzer et al., 2000; Brandt et al., 2003; Brandt, Khimich \& Moser, 2005), while visual signalling relies on stimulus-secretion coupling by retinal Cav1.4 channels (Bech-Hansen et al., 1998; Strom et al., 1998; Mansergh et al., 2005). Some vestibular hair cells, in addition, may involve non-L-type $\mathrm{Ca}^{2+}$ channels (Rodriguez-Contreras \& Yamoah, 2001). Evidence obtained by various techniques in various species all suggests that $\mathrm{Ca}_{\mathrm{V}} 1.3$ channels cluster at the ribbontype active zones of the hair cell. These include loosepatch recordings (Roberts, Jacobs \& Hudspeth, 1990), cell-attached recordings (Rodriguez-Contreras \& Yamoah, 2001), $\mathrm{Ca}^{2+}$ imaging (e.g., Issa \& Hudspeth, 1994; Tucker \& Fettiplace, 1995; Zenisek et al., 2003) and immunohistochemistry (Sidi et al., 2004; Brandt et al., 2005). Estimates of the total number of $\mathrm{Ca}^{2+}$ channels per active zone have been obtained in frog saccular hair cells ( $~ 90$ channels, Roberts et al., 1990; but see also Rodriguez-Contreras \& Yamoah, 2001) and mouse cochlear IHCs ( 80, Brandt et al., 2005) by ensemble fluctuation analysis. This similarity in channel number is unexpected given the size differences between the active zones of the two species (see below and Table 1) and highlights how much more we have to learn about this intriguing synapse.

Classical work by Robert's and Fettiplace's groups on intracellular calcium dynamics at the plasmalemma face of hair cells advocated the view that calcium domains were micromolar in concen- tration and micrometer in dimension. This work was based largely on computational models and studies of calcium-activated potassium channel gating, but was assumed to be also applicable to hair cell afferent synapse exocytosis. However, more recent experiments on the stimulus-secretion coupling in mouse IHCs suggested that exocytic fusion of a given readily releasable vesicle is controlled only by few nearby $\mathrm{Ca}^{2+}$ channels (Brandt et al., 2005). These authors argued that such a "nanodomain" control would support the temporal precision of coding also for weak sounds. Additional experiments using complimentary techniques are needed to further test this provocative hypothesis.

Rim binding protein, interacting with the active zone protein RIM and the $\mathrm{Ca}_{\mathrm{V}} 1.3$ channel, is currently the best characterized candidate for a molecular link of channel and release site of a given vesicle (Hibino et al., 2002). However, functional evidence is still lacking and it remains possible that other proteins, e.g., scaffolding proteins of the cytomatrix of active zones like Bassoon or Piccolo, contribute. It is also possible that the synaptic ribbon itself is responsible for positioning of the $\mathrm{Ca}_{\mathrm{V}} 1.3$ channel and readily releasable vesicles (Khimich et al., 2005). Clearly, molecular work, physiological analysis of mutants and particular immunoelectronmicroscopy are required to characterize the molecular interactions and the ultrastructural topography at the active zone. Figure 2 illustrates the subcellular localization of a few synaptic proteins.

Besides a molecular coupling, other mechanisms contribute to localized $\mathrm{Ca}^{2+}$ signalling. The presence of the mobile, proteinaceous $\mathrm{Ca}^{2+}$ buffers calretinin, calbindin and parvalbumin has now been documented in a variety of cochlear and vestibular hair cells (e.g., Edmonds et al., 2000; Heller et al., 2002; Hackney et al., 2005). Their relevance for presynaptic $\mathrm{Ca}^{2+}$ signalling has been inferred from recordings of $\mathrm{Ca}^{2+}$-activated large-conductance $\mathrm{K}^{+}$channels (Fettiplace, 1992; Roberts, 1993; Tucker \& Fettiplace, 1996; Edmonds et al., 2000), simulations (Roberts, 1994) and capacitance measurements (Moser \& Beutner, 2000; Spassova et al., 2004). Most likely they spatiotemporally restrict the presynaptic $\mathrm{Ca}^{2+}$ domains and, hence, improve the timing of synaptic transmission. However, discrepancies regarding both the amount and kinetic properties of buffers in different hair cells (Roberts, 1993; Edmonds et al., 2000 vs Moser \& Beutner, 2000) suggest that our understanding of calcium buffers at the hair cell active zone synapse is far from complete. Examination of hair cells from mutant mice lacking the major proteinaceous $\mathrm{Ca}^{2+}$ buffers promises further insight into this important question.

In addition to synchronous synaptic transmission, the molecular machinery needs to be suited for long-lasting transmitter release. By yet unknown 

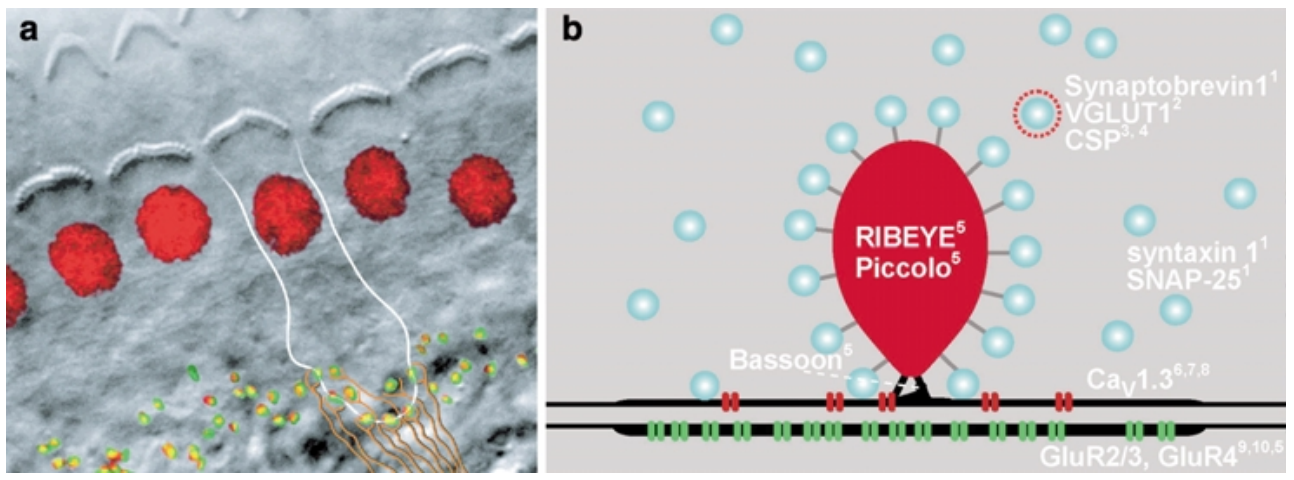

Fig. 2. Molecular composition of the hair cell synapse. (A) Montage of a Nomarski image (note the hair cell bundles) and a confocal reconstruction of the mouse organ of Corti with immunolabeled ribbons (stained for RIBEYE/CtBP2, red) and postsynaptic transmitter receptor clusters (GluR2/3 glutamate receptor subtypes, green). Presumptive hair cell border (white) and postsynaptic fibers (orange) contacting an IHC were drawn illustration. (B) Previously identified molecular determinants of the hair cell ribbon synapse. ${ }^{I}$ Safieddine \& Wenthold, 1999; ${ }^{2}$ Furness \& Lawton, 2003; ${ }^{3}$ Eybalin et al., 2002; ${ }^{4}$ Schmitz et al., 2006; ${ }^{5}$ Khimich et al., 2005; ${ }^{6}$ Platzer et al., 2000; ${ }^{7}$ Brandt, Striessnig \& Moser, 2003; ${ }^{8}$ Brandt, Khimich \& Moser, 2005; ${ }^{9}$ Matsubara et al., 1996; ${ }^{10}$ Eybalin et al., 2004.

mechanisms Cav 1.3 currents in hair cells are much less inactivating than in heterologous expression systems (Koschak et al., 2001). Most likely this is due to interactions with a special combination of auxiliary subunits and proteins, such as the class of $\mathrm{Ca}^{2+}$ binding proteins (Haeseleer et al., 2004). None of these auxiliary determinants of hair cell $\mathrm{Ca}^{2+}$ current are known so far.

Once the neurotransmitter is released into the synaptic cleft, it activates an AMPA-like receptor residing within a receptor cluster at the postsynaptic density of afferent auditory nerve fibers. In a classical study, Ottersen and his colleagues showed the abundance of the glutamate receptor subtypes (GluR) 2, 3 and 4 by immunogold labelling (Matsubara et al., 1996). Interestingly, the distribution of the glutamate receptor was not homogenous in the postsynaptic density (PSD): the receptor numbers increase at the border of the PSD. Using patch-clamp recordings from the postsynaptic endings contacting rat IHCs, Glowatzki \& Fuchs (2002) showed that excitatory postsynaptic currents of spiral ganglion neuron afferent fibres are mediated by AMPA receptors. They failed to detect NMDA or Kainate currents. Recently, Eybalin and colleagues studied the developmental expression changes of postsynaptic glutamate receptors using western blotting, RT-PCR and immunohistochemistry (Eybalin et al., 2004). They showed that GluR2 becomes expressed only around the onset of hearing, while GluR3 and 4 are present before. Little is known about the other molecular determinants of the PSD. Davies et al. (2001) report the presence of PSD-95 and PSD-93 in the PSD of auditory nerve fibres.

To avoid saturation and excitotoxicity due to an excess of glutamate in the synaptic cleft, glutamate is taken up by glutamate transporters (EAAT) into supporting cell transporters (Furness \& Lehre, 1997;
Furness \& Lawton, 2003; Rebillard et al., 2003). Interestingly, glutamate-aspartate transporters (GLA ST) are more abundant on the pillar IHC side, where high spontaneous rate fibers are located, compared to the modiolar cell side, where low spontaneous rate fibres are located (Liberman, 1982; Furness \& Lawton, 2003).

\section{Relating Structural and Functional Vesicle Populations}

\section{MORPHOLOGY}

\section{Synaptic Ribbons}

The active zone of the hair cell is characterized by an electron dense structure called synaptic body or ribbon. Most synaptic ribbons found in mature hair cells are anchored to the plasma membrane, one ribbon per active zone, and oppose a postsynaptic terminal. A small number of "floating" ribbons $(<5 \%)$ are observed, and probably reflect the turnover of these subcellular organelles (Zenisek et al., 2004; Khimich et al., 2005). Shape, size and number of the ribbons differ (see Table 1) between species as well as along the tonotopic axis, during development (Shnerson, Devigne \& Pujol, 1981; Sobkowicz et al., 1982; Khimich et al., 2005) and even among different active zones within a single hair cell (Merchan-Perez \& Liberman, 1996). For example, frog saccular hair cells display about 20 large, synaptic bodies irrespective of the cells' location in the end organ (Roberts et al., 1990; Lenzi et al., 1999, 2002). Whereas in the chick cochlea, the number of synaptic bodies is constant in tall hair cells (functional homologue of the mammalian IHCs), the synaptic body diameter increases with increasing characteristic frequency (Martinez-Dunst, Michaels $\&$ Fuchs, 1997). Conversely, the number of ribbons 
Table 1. Size and kinetics of release components related to the synaptic ribbon and to morphological vessel pools associated from different species.

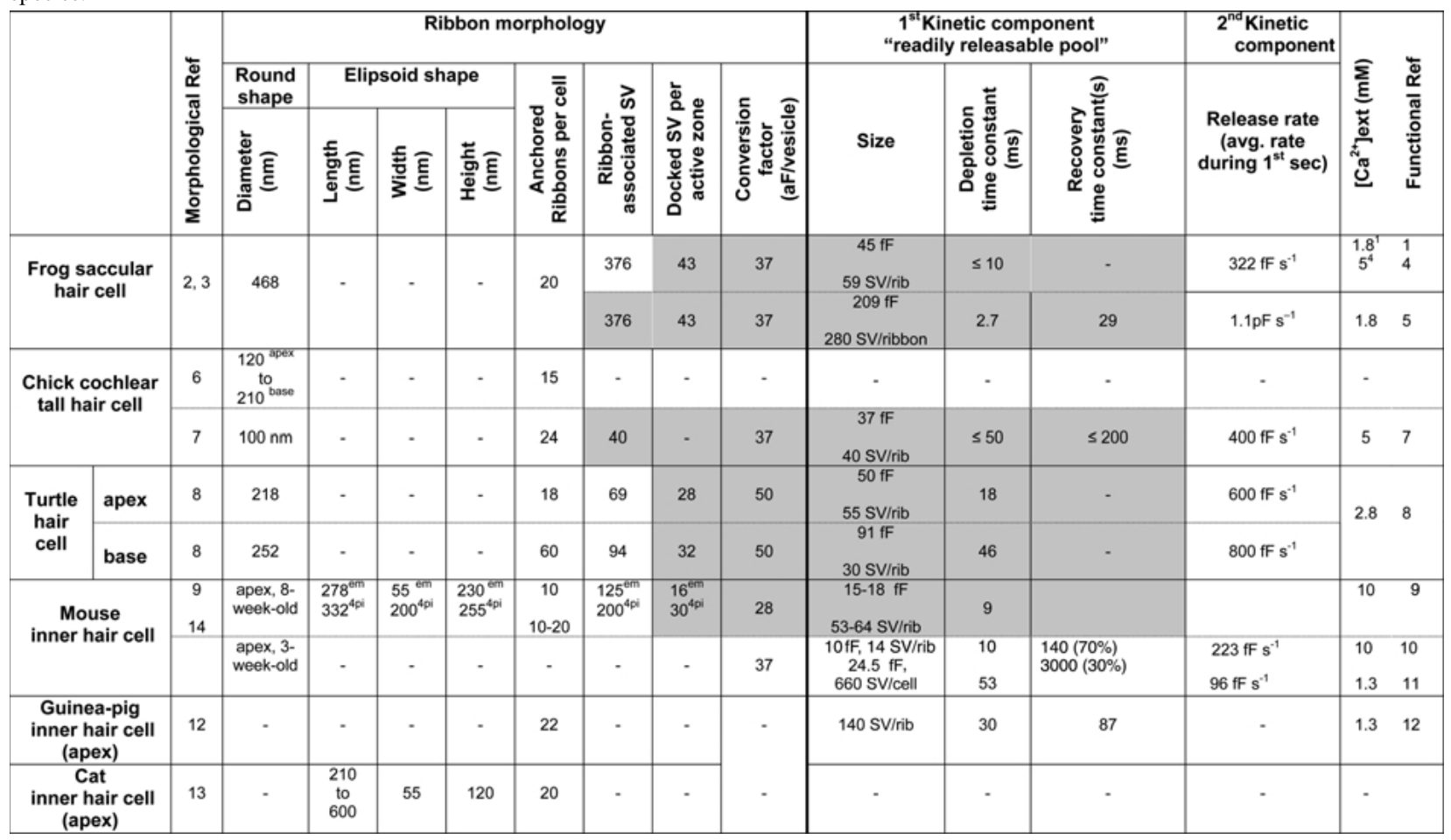

The morphological data have been obtained using electron tomography (Frog), high voltage electron microscopy (Chick), electron microscopy (Turtle, Mouse, Cat) and 4Pi microscopy (Mouse). Ribbon counts were obtained by electron or confocal microscopy. The conversion factor corresponds to one single vesicle's capacitance approximated from the electron microscopic estimate of the vesicle diameter by the different authors. The size (in $\mathrm{fF}$ for the total amplitude and converted into equivalent number of vesicles on average released per ribbon synapse) and kinetics of depletion and recovery (time constant in ms) of the first release component (here interpreted as readily releasable pool) were obtained using capacitance measurements, except for guinea-pig (two-photon imaging). The structural interpretation of the first kinetic component of release by the authors is indicated by gray boxes. To compile the data available on the second kinetic component of the capacitance rise, we approximated the average rate during the first second following saturation of the readily releasable pool in the various studies. In accordance with our interpretation that extrasynaptic exocytosis contributes significantly, we did not relate the release to the number of synapses. The estimates were mostly obtained using maximal stimulation (depolarization to achieve the peak calcium current), but extracellular $\mathrm{Ca}^{2+}$ concentrations differed in the various studies. References: 1, Rutherford, \& Roberts, 2006; 2, Roberts, Jacobs \& Hudspeth, 1990; 3, Lenzi et al., 1999; 4, Parsons et al., 1994; 5, Edmonds, Gregory \& Schweizer, 2004; 6, MartinezDunst, Michaels \& Fuchs, 1997; 7, Spassova et al., 2004; 8, Schnee et al., 2005; 9, Khimich et al., 2005; 10, Moser \& Beutner, 2000; 11, Johnson, Marcotti \& Kros, 2005; 12, Griesinger, Richards \& Ashmore, 2005; 13, Liberman, 1980; 14, Francis et al., 2004.

varies along the tonotopic axis in many other species including turtle (plus small size differences: Sneary, 1988; Schnee et al., 2005), cat (Liberman, Dodds \& Pierce, 1990), gerbil (Slepecky et al., 2000) and guinea pig (Hashimoto, Kimura \& Takasaka, 1990).

Both the number and shape of the synaptic ribbons can also change with the onset of hearing. Mouse IHCs contain a large number $(>20$ in the apical cochlea, Nemzou et al., unpublished data) of small synaptic bodies (Shnerson et al., 1981; Sobkowicz et al., 1982) before the onset of hearing. After the onset of hearing only fewer but larger ellipsoid ribbons are observed (Shnerson et al., 1981; Sobkowicz et al., 1982; Francis et al., 2004; Khimich et al., 2005). An interesting feature described for cat IHCs is the spatial segregation of synapses with fibres of different spontaneous rates and thresholds. Thus, low-spontaneousrate, high-threshold fibres contact the IHCs on their modiolar side, whereas high-spontaneous-rate, lowthreshold fibres synapse on the pillar IHC side. EM analysis showed that the ribbon size and accordingly the number of ribbon-associated synaptic vesicles tend to increase with decreasing spontaneous rate of the contacted fibres (Liberman, 1980; Liberman et al., 1990; Merchan-Perez \& Liberman, 1996).

\section{Synaptic vesicles}

Ribbons tether a monolayer of synaptic vesicles at a packing density that is $\sim 55 \%$ of maximum by $20 \mathrm{~nm}$ long filaments (Lenzi et al., 1999). These ribbonassociated vesicles represent only a tiny fraction of the huge number of synaptic vesicles contained in a hair cell. At least three vesicle populations can be morphologically distinguished at the hair cell ribbon synapse as illustrated by Figure 3: 

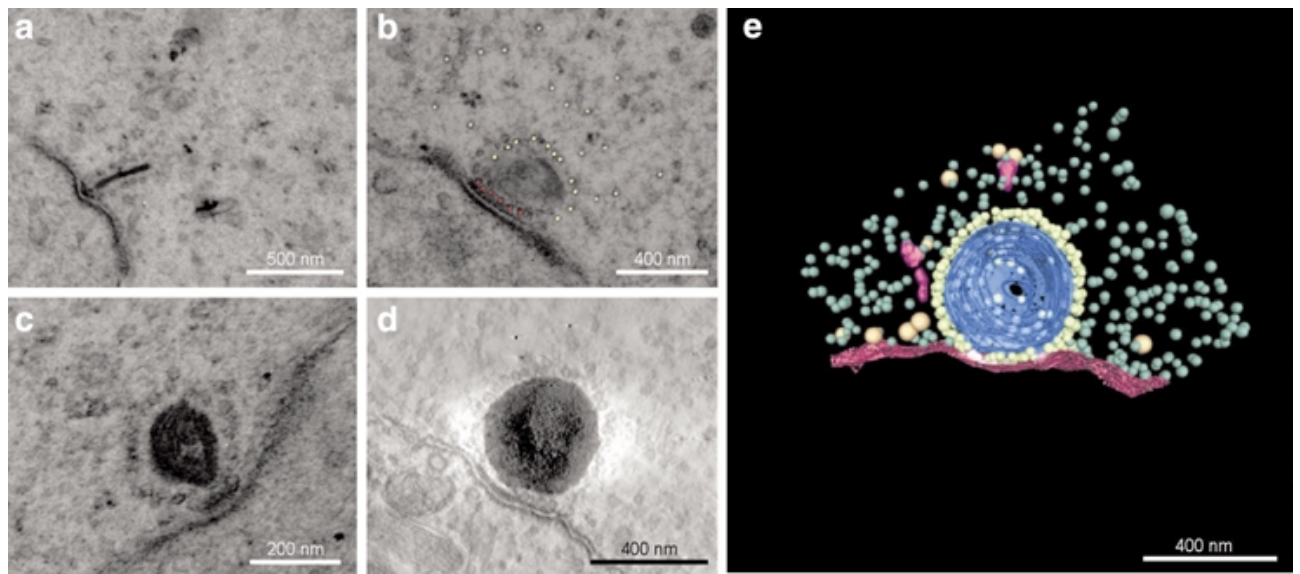

Fig. 3. Morphology of synaptic ribbons. ( $a, b$ and $c$ ) Electron micrographs of inner hair cell ribbon synapses of 8-week-old mouse. Ribbons are attached to the plasma membrane and surrounded by a monolayer of synaptic vesicles. Colored dots in $(b)$ illustrate the morphologically defined classes of synaptic vesicles: red dots indicate the docked vesicle associated with the ribbon; yellow marks ribbon- associated SV which are not docked and green indicates outlying cytoplasmic vesicles. (d) Slice through an osmium-stained frog saccular hair cell synapse, reconstructed by electron tomography. Note the round shape of the synaptic body in contrast to the elipsoid one of the mouse. (e) Threedimensional structure of presynaptic organelles from the same reconstruction shown in (d). The synaptic body (blue) is open and lies adjacent to the hair cell's plasma membrane in red. Synaptic body-associated vesicles (yellow) surround the SB; outlying vesicles (green) lie further out in the cytoplasm. Also visible are coated vesicles (gold) and cisterns (purple).

- Docked vesicles (no discernible space between vesicle and plasma membranes)

- Ribbon-associated vesicles

- Free cytosolic synaptic vesicles.

These vesicle populations have been quantified for hair cells of various species (Table 1). A variety of approaches have been used to assess the vesicle populations and accordingly, varying degrees of certainty surround these vesicle counts. The different approaches have included: precise three-dimensional EM counts based on few synapses (EM tomography: Fig 3, Lenzi et al., 1999; Lenzi et al., 2002; reconstructions based on ultrathin serial sections: Schnee et al., 2005); extrapolations from random ultrathin EM sections of tens of synapses (Khimich et al., 2005) and approximations based on ribbon surface areas and vesicle packing density estimates (Spassova et al., 2004; Khimich et al., 2005: more than 200 ribbons analyzed).

Docked vesicles at a conventional synapse are viewed as a homogeneous anatomical pool. However, at the hair cell ribbon synapse docked vesicles are found in a variety of anatomical states; this includes underneath the ribbon (docked and ribbon-associated), at the active zone without contact to the ribbon, and outside the active zone. Lenzi et al., (1999) termed these last two classes of docked vesicles as "outlying". The functional implications of the different classes of docked vesicles are poorly understood. Obviously, proximity to a calcium channel increases the likelihood that a docked vesicle is of functional significance. Accordingly, Lenzi et al., (1999) attempted to correlate the positions of docked vesicles and $\mathrm{Ca}^{2+}$ channels at the active zone. While the "outlying" vesicles are substantial in number, they are located further from the presumed calcium channel containing presynaptic densities than are other docked vesicles. "Outliers" has been alternatively used in evanescent wave microscopic studies (Zenisek, Steyer \& Almers, 2000) to describe the "docking" and fusion of synaptic vesicles outside of functionally defined active zones.

\section{Physiology}

One fruitful way to investigate the compact afferent presynaptic terminal of the inner ear is to monitor exocytic fusion and endocytic retrieval of synaptic vesicle membrane as changes of the membrane capacitance $\left(C_{\mathrm{m}}\right)$ using the patch-clamp technique (for review see Neher, 1998). During the fusion of the synaptic vesicle to the plasma membrane the cell surface and consequently $C_{\mathrm{m}}$ increase. This then is usually followed by slower fission accompanying $C_{\mathrm{m}}$ decrease. This technique has become increasingly popular to study the presynaptic function of hair cells in various species (Table 1). Upon depolarization, calcium influx, mainly through $\mathrm{Ca}_{V} 1.3 \mathrm{~L}$-type $\mathrm{Ca}^{2+}$ channels, triggers exocytosis of readily releasable synaptic vesicles. Depending on the stimulus intensity and duration, the resulting $C_{\mathrm{m}}$ increase may report exocytosis occurring at all active zones as well as the fusion of synaptic vesicles outside of active zones or even the fusion of non-synaptic membrane organelles (Coorssen, Schmitt \& Almers, 1996). This lack of specificity associated with capacitance measurements can complicate its interpretation. 
At least two kinetic components of exocytosis are commonly discriminated in the recordings of hair cell membrane capacitance following stimuli thought to trigger exocytosis. Such findings from a variety of species are also summarized in Table 1.

The first kinetic component of these membrane capacitance increases mediates exocytosis at extremely high rates but saturates within a few milliseconds. Hence, it is generally agreed that this component represents exocytosis of a small, finite pool of vesicles. Because it is the fastest discernible and exhaustible component of exocytosis several authors denominated it the readily releasable vesicle pool (RRP, Moser \& Beutner, 2000; Spassova et al., 2004; Rutherford \& Roberts, 2006) following the classical terminology of functional vesicle pools (Liley \& North, 1953; Birks \& MacIntosh 1961; Elmqvist \& Quastel, 1965). Three major findings indicate that the first kinetic component is, indeed, involved in synaptic sound-coding by hair cells:

- Correlation between the RRP size and the number of afferent synapses made by a hair cell as it varies along the tonotopic axis of the cochlea (Schnee et al., 2005).

- Correlation between the RRP size and the number of synapse-anchored ribbons (Khimich et al., 2005).

- Correlation between the RRP size and the amplitude of the spiral ganglion compound action potential (reflecting synchronous activation of spiral ganglion neurons) (Khimich et al., 2005).

Several other lines of evidence support the notion that the first kinetic component of exocytosis represents a synaptic relative pool of vesicles. Resistance of the readily releasable pool to inhibition by exogenous slow calcium buffers infers a co-localization of this functional pool with $\mathrm{Ca}^{2+}$ channels (Moser \& Beutner, 2000; Spassova et al., 2004). Calcium channels are widely believed to be concentrated at hair cell active zones (e.g., Roberts et al., 1990; Issa \& Hudspeth, 1994; Tucker \& Fettiplace, 1995; Zenisek et al., 2003; Sidi et al., 2004; Brandt et al., 2005). Nanodomain control of synaptic vesicle exocytosis (Brandt et al., 2005) requires an intimate spatial relationship between the readily releasable pool and calcium channels. There is also good correspondence between the quantal content predicted by measurement of action potential-driven exocytic $C_{\mathrm{m}}$ changes in immature IHCs (Beutner \& Moser, 2001; Johnson, Marcotti \& Kros, 2005) and direct measures of postsynaptic currents from the afferent fiber (Glowatzki \& Fuchs, 2002). Finally, additional supportive evidence comes from comparison of the timing of peripheral auditory adaptation and the kinetics of RRP depletion and recovery.

Adaptation is a common property of sensory systems. It reduces encoding redundancy by decreasing the sensitivity to constant stimulation, is proposed to optimize a sensory system's operating range (Koutalos \& Yau, 1996) and maximize its information transfer (Brenner, Bialek \& de Ruyter van Steveninck, 2000). In the peripheral auditory system, adaptation is likely localized to the cochlear hair cell afferent synapse because hair cell receptor potentials do not adapt to maintained acoustic stimulation (Holton \& Weiss, 1983; Russell \& Sellick, 1978). Previous work (Furukawa \& Matsuura, 1978; Moser \& Beutner, 2000) suggested that the exhaustion and replenishment of the readily releasable pool of vesicles in the hair cell contribute to a fast form of adaptation and recovery from it in the auditory nerve (Westerman \& Smith, 1984; Yates, Robertson \& Johnstone, 1985).

Parsons and colleagues (Spassova et al., 2004) employed both in vitro patch-clamp recordings of hair cell synaptic vesicle fusion and in vivo single-unit recording of cochlear nerve activity at the same synapse to further examine this hypothesis and probe the possible auditory significance of the hair cell ribbon synapse structure-function relationship. Similar to other hair cell preparations, exocytosis of the chick cochlear tall cell's readily releasable pool is fast, saturating in $<50 \mathrm{~ms}$, and its recovery is also rapid, regaining $95 \%$ of its initial amplitude following a 200 $\mathrm{ms}$ period of repolarization. Interestingly, soundevoked afferent synaptic activity also adapted and recovered with similar time courses as readily releasable pool exhaustion and recovery. This work supports the view that the fast exocytic component is of synaptic relevance by providing evidence that exhaustion and replenishment of the readily releasable pool mediates behaviorally relevant phenomena - namely short-term auditory nerve adaptation and its recovery from adaptation.

In an elegant two-photon imaging study Ashmore and colleagues utilized the turnover of the membrane dye FM1-43 to track the exocytosis of synaptic vesicles at hair cell active zones. Their findings on the readily releasable pool of the adult guinea pig IHCs were similar to descriptions provided in other species by capacitance measurements. The significance of these findings is that the imaging experiments, unlike the capacitance measurements, are spatially resolved and lend credence to previous interpretations of the first exocytic component. Optically recorded exocytosis was extremely fast at the onset of a depolarization (initial rate of 3,000 vesicles per second) and saturated with a time constant of $30 \mathrm{~ms}$ in mature guinea pig hair cells (Griesinger, Richards \& Ashmore, 2005). This intial rate is comparable to the initial rate of exocytosis evoked at one ribbon synapse of mature mouse IHCs by maximal stimulation amounting to $\sim 6,000$ vesicles per second (after $C_{\mathrm{m}}$ conversion into vesicle numbers using $28 \mathrm{aF} /$ vesicle). Moreover, estimates of the time course of recovery from depletion obtained by the two methods were quite similar, too (Table 1). 
Both the amplitude and kinetics of the first kinetic component in mature mouse and guinea-pig hair cells were found to depend on the stimulus strength (Brandt et al., 2005; Griesinger et al., 2005). This is in contrast to a study on frog saccular hair cell exocytosis where the kinetics, but not amplitude of exocytosis, varied with stimulus amplitude (Edmonds, Gregory \& Schweizer, 2004). The reasons for this discrepancy among the different experiments are currently unclear. Moser and colleagues have suggested the $\mathrm{Ca}^{2+}$ nanodomain control of RRP exocytosis in mouse IHCs (Brandt et al., 2005). This hypothesis predicts that an increase in intensity of stimuli would recruit more calcium channel-release site units, presumably increasing the amplitude of the RRP without major changes of release kinetics. Classical quantal analysis at the goldfish hair cell synapse (Furukawa, Kuno \& Matsuura, 1982) also revealed intensity-dependent increases in the number of available vesicles (as opposed to changes in the release probability). While the synaptic relevance of the first kinetic component is indisputable, clearly a detailed mechanistic understanding of it awaits further experimentation.

Our current knowledge about the further kinetic component (s) is much more limited. This is mainly due to the lack of spatial resolution of $C_{\mathrm{m}}$ recordings of exocytosis, which report fusion to the plasma membrane no matter whether it happens at the synapse or elsewhere. The slower kinetic components are typically triggered by prolonged, strong depolarizing steps (tens of $\mathrm{ms}$ to $\mathrm{s}$ in duration) and have the potential to drive calcium levels within the cell to levels that could not be achieved with more physiological time-varying, smaller-amplitude stimuli. The relative resistance of the $\mathrm{Ca}_{\mathrm{V}} 1.3$ calcium channel to inactivation allows for the influx of large numbers of calcium ions during prolonged depolarizations that may be sufficient to saturate cellular calcium buffers. Clearly, aphysiologic calcium gradients within the hair cell promise to further compound the limitations of membrane capacitance measurements and cloud the interpretation of secondary, slower exocytic components.

Since the first $C_{\mathrm{m}}$ measurements of hair cell exocytosis (Parsons et al., 1994), we have been astonished and puzzled by the huge amount of membrane turnover during prolonged depolarization. During the first second of depolarization thousands of vesicles are released (see Table 1). A membrane turnover of more than one equivalent of the initial hair cell's surface has been reported for maximal stimulation over several seconds (Schnee et al., 2005). In this respect, the hair cell's exocytic capacity exceeds that of retinal photoreceptors and bipolar neurons. This difference between retinal cells and hair cells is most dramatic when examining the fast exocytosis evoked by $\mathrm{Ca}^{2+}$ uncaging. A uniform step increase in calcium concentration through the cell's cytoplasm triggers the exocytosis of all fusion-competent vesicles. Flash photolysis of caged calcium in the goldfish bipolar nerve terminal results in an average capacitance increase of $\sim 150 \mathrm{fF}$ (Heidelberger et al., 1994), whereas a similar stimulus in the mouse IHC drives a 10-fold larger increase in membrane capacitance (Beutner et al., 2001). This discrepancy in the amount of exocytosis is even more remarkable given that a hair cell contains nearly 4 times fewer, but similar-sized and vesicle-populated synaptic ribbon active zones as the retinal bipolar terminal (von Gersdorff et al., 1996; Khimich et al., 2005). Hence we have to either assume that the turnover at a hair cell ribbon synapse is 40 times faster than that of a bipolar neuron or to conclude that hair cells contain an extremely large pool of fusion-competent vesicles that reside outside of the active zone. Spatially-resolved exocytic measurements, such as imaging or conventional post-synaptic recordings, will be required to ascertain the contribution of the hair cell's large pool of fusigenic vesicles to synaptic relevant exocytosis.

\section{Is it Possible at all to Relate Anatomically and Physiologically Defined Pools of Synaptic Vesicles?}

It would be a significant breakthrough in our understanding of the hair cell ribbon synapse if we managed to arrive at a joint anatomical and physiological definition of synaptic vesicle populations. This goal requires relating physiologically derived capacitance or fluorescence changes to anatomically defined synaptic vesicle numbers. Unfortunately, several technical issues limit the accuracy and certainty of this pursuit. Estimations of single-vesicle capacitance are required to determine the equivalent number of vesicles associated with a given $C_{\mathrm{m}}$ increase. Surface calculations based on the vesicle diameter in fixed tissue (possibly correcting for a potential shrinkage bias) and an assumption of the specific membrane capacitance (usually $10 \mu \mathrm{F} / \mu \mathrm{m}^{2}$, Breckenridge \& Almers, 1987) are commonly employed. Both are prone to errors complicating this structure-function approach. The inherent problems with the fixation artefacts are highlighted by the factor of 2 discrepancy between "in vitro" single-vesicle capacitance values derived from anatomical studies $(37 \mathrm{aF}$, Lenzi et al., 1999 and $28 \mathrm{aF}$, Khimich et al., 2005) and the more direct "in vivo" estimates obtained by electrophysiology in other systems $(\sim 50 \mathrm{aF}$, Klyachko \& Jackson, 2002 and $65 \mathrm{aF}$, Sun, $\mathrm{Wu} \& \mathrm{Wu}, 2002)$.

The physiological approach to pool definition also faces technical limitations. The rate of the first or fastest kinetic component is limited by the bandwidth and signal-to-noise ratio of the recording equipment. Much confusion in the retinal bipolar terminal literature stems from the initial definition 
of a readily releasable pool with a time constant of $\sim 100 \mathrm{~ms}$ (von Gersdorff \& Matthews, 1994) prior to the subsequent discovery of a 5-fold smaller, but nearly 50-fold faster kinetic component of exocytosis (Mennerick \& Matthews, 1996; Neves \& Lagnado, 1999). At the chick hair cell synapse, which features some of the smallest-numbered and -sized synaptic ribbons, the total number of docked vesicles is $\sim 100$. Exocytosis of these vesicles would generate a capacitance increase perhaps as small as $3 \mathrm{fF}$, at or below the resolution of whole-cell capacitance measures and likely obscuring the observation of this pool that is readily measured in cells with large ribbon structures.

\section{What Is the Anatomical Substrate of the Fast Kinetic Component in Hair Cell Exocytosis?}

Several caveats described above constrain our ability to answer this question. However, recognizing these limitations and uncertainties, it remains an important and interesting question underlying our understanding of the hair cell afferent synapse. The recent literature provides two alternative hypotheses: it may preferentially draw on readily releasable vesicles docked at the plasma membrane of the active zone (Moser \& Beutner, 2000; Khimich et al., 2005; Schnee et al., 2005; Rutherford \& Roberts, 2006) or involve release of all ribbon-associated vesicles (Edmonds et al., 2004; Spassova et al., 2004). Table 1 highlights these views. The first hypothesis is consistent with independent fusion of the individual vesicles, similar to what is expected for docked vesicles at the active zone of conventional synapses. The second hypothesis requires the rapid recruitment and fusion of nondocked ribbon-associated vesicles. As active vesicle transport seems too slow (see discussion in Edmonds et al., 2004), different modes of exocytosis, such as compound and "piggy back" (cumulative) fusion, have been considered (Parsons \& Sterling, 2003; Edmonds et al., 2004; Spassova et al., 2004). Functional evidence for multivesicular release at the hair cell ribbon synapse was first obtained by Glowatzki and Fuchs (2002). Using direct post-synaptic recordings at rat afferent synapses, they observed large variations in the amplitude of kinetically quite homogeneous postsynaptic currents, as well as clear composite events characterized by multiple quanta (Glowatzki \& Fuchs, 2002). Clearly, the exact presynaptic release mechanism of vesicle release is likely to have great impact on the transfer characteristics of the hair cell synapse and remains an extremely important problem for continued study.

This review cannot solve the debate over the anatomical basis of the hair cell fast exocytic component. However, we aim to fuel the on-going discussion with some selected comparisons of data complied from various studies and summarized in Table 1. Any considerations of structure-function comparisons are complicated by the fact that the physiological pool size estimates obtained by different groups can vary substantially even for hair cells of the same species (Edmonds et al., 2004; Rutherford \& Roberts, 2006, see discussion in Rutherford' paper). Moreover, the morphological vesicle counts or estimations vary dramatically in their degree of precision (from direct counts in electron microscopical 3-D reconstructions to approximations based on ribbon size, see Morphology section above and Table 1). In addition, we need to remember that our capacitancebased approximations probably overestimate the number of vesicles due to underestimation of singlevesicle capacitances (due to the shrinkage during chemical fixation, see above). With these caveats in mind, studies on hair cells of the frog (work from the Roberts lab) and the mouse (work from the Moser lab) provide the most compelling structure-function correlations, in part because both the anatomy and physiology were carried out in the same laboratory. In each case, their observations support the hypothesis that for these particular hair cells RRP is defined by the fusion of docked vesicles (Table 1). Correcting the conversion factor for shrinkage would tend to still improve the match between RRP size and docked vesicle number.

The question still lingers as to whether nondocked vesicles can be released rapidly at ribbon synapses. Zenisek et al. (2000), using evanescent wave microscopy of single FM1-43 stained vesicles in retinal bipolar nerve terminals, provide some of the most direct evidence addressing this question. They reported that the first component of exocytosis was dominated by "resident" (probably docked) vesicles at the hotspots of exocytosis, whereas arrivals or "newcomers" contributed only marginally within the first milliseconds. This argues against a major contribution of nondocked, ribbon-associated vesicles. On the other hand, Griesinger et al. (2005) concluded from two-photon imaging of basolateral hot-spots of FM1-43 fluorescence that rapid exocytosis of non-docked vesicles does, indeed, occur at hair cell ribbon synapses. A certain degree of caution, however, is required in interpreting either of these studies, as the best resolution of an optical microscope $(200 \mathrm{~nm})$ is comparable to the size of most synaptic ribbons.

The apparent differences between the behavior of ribbon-tethered vesicles in these two types of ribbon synapses highlight the fact that it could be an oversimplification to assume that a common anatomical substrate underlies the first/fastest recorded kinetic component of hair cell exocytosis. The physical dimensions of hair cell active zones, shapes of synaptic ribbons, best stimulation frequency, and possibly endogenous calcium buffering vary dramatically across end organ, species and in some cases even 
within the same end organ of a given species. Thus, subsequent studies may reveal that different hair cells use different anatomical substrates for different functional pools of synaptic vesicles to meet their respective synaptic demands.

\section{What about the Anatomical Substrate of Subsequent, Slower Kinetic Components of Exocytosis?}

Things are still more complicated for the further kinetic component(s) of exocytosis reported by capacitance measurements. Most studies concur that replenishment of readily releasable vesicles occurs at high rates, exceeding those of conventional synapses and even retinal ribbon synapses (Moser \& Beutner, 2000; Spassova et al., 2004; Edmonds et al., 2004; Griesinger et al., 2005). However, whether the slow kinetic components of exocytosis simply represent the serial refilling of the readily releasable pool and or parallel exocytosis at "ectopic" fusion sites is debatable. Schnee et al. (2005) proposed a purely serial and synaptic model to explain the three kinetic components of the depolarization-induced exocytic $C_{\mathrm{m}}$ changes in turtle hair cells. They inferred that the second component reflected exocytic turnover of the ribbon-associated vesicle population, while vesicle recruitment to the ribbon would become rate-limiting thereafter. Not surprisingly, a similar model was appropriate to describe destaining of FM1-43 hotspots and recovery of staining in the study of Griesinger and colleagues. However, these optical studies differ from the capacitance recordings in the turtle hair cell (Schnee et al., 2005), as they are spatially resolved and focus on membrane turnover at individual active zones.

Findings that argue for a significant contribution of ribbon-independent and at least in part parallel extrasynaptic exocytosis to sustained exocytic $C_{\mathrm{m}}$ changes include:

- Robust sustained exocytosis in hair cells that lack 90\% of their synapse-anchored ribbons (Khimich et al., 2005)

- Presence of docked synaptic vesicles at extrasynaptic stretches of the plasmamembrane (Lenzi et al., 1999, 2002)

- The extensive fast exocytosis during flash photollysis, which by far exceeds fusion of the readily releasable pool (Beutner et al., 2001), potentially arguing for the presence of many fusion-competent vesicles outside the active zone.

In addition, exocytosis of such "outlying" vesicles has been described in retinal bipolar nerve terminals by evanescent microscopy (Zenisek et al., 2000). Hence, taken together, present evidence supports the interpretation that sustained hair cell exocytosis re- ported by $C_{\mathrm{m}}$ tracking represents both the serial resupply of vesicles to the active zones and the parallel extrasynaptic turnover of synaptic vesicles. However, the quantitative contribution of the slow exocytic components to synaptically relevant neurotransmitter release remains to be determined.

\section{Conclusion and Outlook}

The multidisciplinary approach to the hair cell ribbon synapse has for the first time quantitatively described important aspects of the synapse's structure and function. Most importantly, despite all limiting uncertainty, we begin to relate molecules, structure and function. Although still debated, the concept of a readily releasable pool has been substantiated for the ribbon synapse of several hair cells. We have gained a few insights into the mechanisms underlying the incredible temporal precision of synapses that participate in the coding of sound. Moreover, in addition to learning about the molecular physiology, the availability of mouse mutants with defined synaptic lesions provided the possibility to study the properties of synaptopathic hearing impairment in greater detail. However, we are far from a comprehensive molecularly defined model of ribbon structure and function. The molecular dissection of the hair cell synapse is technically challenging due to the low amount of tissue and will require much more time and effort. Ear-specific genetic deletion also will be helpful to investigate synaptic protein function in hair cell sound coding. A more precise and direct biophysical analysis of single hair cell synapses will require combined pre- and postsynaptic recordings as well as optical measurements, such as evanescent wave microscopy and confocal techniques. The optical approach will be strongly facilitated by the generation of genetically targeted fluorescent vesicle tags.

Work in the Moser lab was supported by grants of the DFG (SFB406 and CMPB), the European Commission (through the integrated project EuroHear), the Human Frontiers Science Program (HFSP) and the federal goverment (through the Bernstein Center for Computational Neuroscience, Goettingen). Work by the Parsons lab has been supported by NIH (R01 DC3783), HFSP (RG0124), and the Pennsylvania Lions Club. We would like to thank R. Pujol for providing EM images (mouse IHCs, Figure 3) and critical reading of the manuscript, and W.R. Roberts for providing the tomography image and reconstruction of Figure 3.

\section{References}

Altrock, W.D., tom Dieck, S., Sokolov, M., Meyer, A.C., Sigler, A., Brakebusch, C., Fassler, R., Richter, K., Boeckers, T.M., Potschka, H., Brandt, C., Loscher, W., Grimberg, D., Dresbach, T., Hempelmann, A., Hassan, H., Balschun, D., Frey, J.U., Brandstatter, J.H., Garner, C.C., Rosenmund, C., Gun- 
delfinger, E.D. 2003. Functional inactivation of a fraction of excitatory synapses in mice deficient for the active zone protein bassoon. Neuron 37:787-800

Bech-Hansen, N.T., Naylor, M.J., Maybaum, T.A., Pearce, W.G., Koop, B., Fishman, G.A., Mets, M., Musarella, M.A., Boycott, K.M. 1998. Loss-of-function mutations in a calcium-channel alphal-subunit gene in Xp11.23 cause incomplete X-linked congenital stationary night blindness. Nat. Genet. 19:264-267

Beutner, D., Moser, T. 2001. The presynaptic function of mouse cochlear inner hair cells during development of hearing. $J$. Neurosci. 21:4593-4599

Beutner, D., Voets, T., Neher, E., Moser, T. 2001. Calcium dependence of exocytosis and endocytosis at the cochlear inner hair cell afferent synapse. Neuron 29:681-690

Birks, R., MacIntosh, F.C. 1961. Acetylcholine metabolism of a sympathetic ganglion. Can. J. Biochem. Physiol 39:787-827

Brandt, A., Khimich, D., Moser, T. 2005. Few CaV1.3 channels regulate the exocytosis of a synaptic vesicle at the hair cell ribbon synapse. J. Neurosci. 25:11577-11585

Brandt, A., Striessnig, J., Moser, T. 2003. CaV1.3 channels are essential for development and presynaptic activity of cochlear inner hair cells. J. Neurosci. 23:10832-10840

Breckenridge, L.J., Almers, W. 1987. Final steps in exocytosis observed in a cell with giant secretory granules. Proc. Natl. Acad. Sci. USA 84:1945-1949

Brenner, N., Bialek, W., de Ruyter van cSteveninck, R. 2000. Adaptive rescaling maximizes information transmission. Neuron 26:695-702

Coorssen, J.R., Schmitt, H., Almers, W. 1996. $\mathrm{Ca}^{2+}$ triggers massive exocytosis in Chinese hamster ovary cells. Embo $J$. 15:3787-3791

Davies, C., Tingley, D., Kachar, B., Wenthold, R.J., Petralia, R.S. 2001. Distribution of members of the PSD-95 family of MAGUK proteins at the synaptic region of inner and outer hair cells of the guinea pig cochlea. Synapse 40:258-268

Dick, O., Hack, I., Altrock, W.D., Garner, C.C., Gundelfinger, E.D., Brandstatter, J.H. 2001. Localization of the presynaptic cytomatrix protein Piccolo at ribbon and conventional synapses in the rat retina: comparison with Bassoon. J. Comp. Neurol. 439:224-234

Dick, O., tom Dieck, S., Altrock, W.D., Ammermuller, J., Weiler, R., Garner, C.C., Gundelfinger, E.D., Brandstatter, J.H. 2003. The presynaptic active zone protein bassoon is essential for photoreceptor ribbon synapse formation in the retina. Neuron 37:775-786

Edmonds, B., Reyes, R., Schwaller, B., Roberts, W.M. 2000. Calretinin modifies presynaptic calcium signaling in frog saccular hair cells. Nat. Neurosci. 3:786-790

Edmonds, B.W., Gregory, F.D., Schweizer, F.E. 2004. Evidence that fast exocytosis can be predominantly mediated by vesicles not docked at active zones in frog saccular hair cells. J. Physiol. 560: $439-450$

Elmqvist, D., Quastel, D.M. 1965. A quantitative study of endplate potentials in isolated human muscle. J. Physiol. 178:505529

Eybalin, M., Caicedo, A., Renard, N., Ruel, J., Puel, J.L. 2004. Transient $\mathrm{Ca}^{2+}$-permeable AMPA receptors in postnatal rat primary auditory neurons. Eur. J. Neurosci. 20:2981-2989

Eybalin, M., Renard, N., Aure, F., Safieddine, S. 2002. Cysteinestring protein in inner hair cells of the organ of Corti: synaptic expression and upregulation at the onset of hearing. Eur.J. Neurosci. 15:1409-1420

Favre, D., Scarfone, E., Di Gioia, G., De Camilli, P., Dememes, D. 1986. Presence of synapsin I in afferent and efferent nerve endings of vestibular sensory epithelia. Brain Res. 384:379382
Fettiplace, R. 1992. The role of calcium in hair cell transduction. Soc. Gen. Physiol. Ser. 47:343-356

Francis, H.W., Rivas, A., Lehar, M., Ryugo, D.K. 2004. Two types of afferent terminals innervate cochlear inner hair cells in C57BL/6J mice. Brain Res. 1016:182-194

Furness, D.N., Lawton, D.M. 2003. Comparative distribution of glutamate transporters and receptors in relation to afferent innervation density in the mammalian cochlea. J. Neurosci. 23:11296-11304

Furness, D.N., Lehre, K.P. 1997. Immunocytochemical localization of a high-affinity glutamate-aspartate transporter, GLAST, in the rat and guinea-pig cochlea. Eur. J. Neurosci. 9:1961-1969

Furukawa, T., Matsuura, S. 1978. Adaptive rundown of excitatory post-synaptic potentials at synapses between hair cells and eight nerve fibres in the goldfish. J. Physiol. 276:193-209

Furukawa, T., Kuno, M., Matsuura, S. 1982. Quantal analysis of a decremental response at hair cell-afferent fibre synapses in the goldfish sacculus. J. Physiol. 322:181-195

Gallop, J.L., Butler, P.J., McMahon, H.T. 2005. Endophilin and $\mathrm{CtBP} / \mathrm{BARS}$ are not acyl transferases in endocytosis or Golgi fission. Nature 438:675-678

Glowatzki, E., Fuchs, P.A. 2002. Transmitter release at the hair cell ribbon synapse. Nat. Neurosci. 5:147-154

Griesinger, C.B., Richards, C.D., Ashmore, J.F. 2005. Fast vesicle replenishment allows indefatigable signalling at the first auditory synapse. Nature 435:212-215

Hackney, C.M., Mahendrasingam, S., Penn, A., Fettiplace, R. 2005. The concentrations of calcium-buffering proteins in mammalian cochlear hair cells. J. Neurosci. 25:7867-7875

Haeseleer, F., Imanishi, Y., Maeda, T., Possin, D.E., Maeda, A., Lee, A., Rieke, F., Palczewski, K. 2004. Essential role of $\mathrm{Ca}^{2+}$ binding protein 4 , a Cav1.4 channel regulator, in photoreceptor synaptic function. Nat. Neurosci. 7:1079-1087

Hashimoto, S., Kimura, R.S., Takasaka, T. 1990. Computer-aided three-dimensional reconstruction of the inner hair cells and their nerve endings in the guinea pig cochlea. Acta Otolaryngol. 109:228-234

Heidelberger, R., Heinemann, C., Neher, E., Matthews, G. 1994. Calcium dependence of the rate of exocytosis in a synaptic terminal. Nature 371:513-515

Heller, S., Bell, A.M., Denis, C.S., Choe, Y., Hudspeth, A.J. 2002. Parvalbumin 3 is an abundant $\mathrm{Ca}^{2+}$ buffer in hair cells. $J$. Assoc. Res. Otolaryngol. 3:488-498

Hibino, H., Pironkova, R., Onwumere, O., Vologodskaia, M., Hudspeth, A.J., Lesage, F. 2002. RIM binding proteins (RBPs) couple Rab3-interacting molecules (RIMs) to voltage-gated $\mathrm{Ca}^{2+}$ channels. Neuron 34:411-423

Holton, T., Weiss, T.F. 1983. Receptor potentials of lizard cochlear hair cells with free-standing stereocilia in response to tones. J. Physiol. 345:205-240

Issa, N.P., Hudspeth, A.J. 1994. Clustering of $\mathrm{Ca}^{2+}$ channels and $\mathrm{Ca}^{2+}$-activated $\mathrm{K}^{+}$channels at fluorescently labeled presynaptic active zones of hair cells. Proc. Natl. Acad. Sci. USA 91:7578-7582

Johnson, S.L., Marcotti, W., Kros, C.J. 2005. Increase in efficiency and reduction in $\mathrm{Ca}^{2+}$ dependence of exocytosis during development of mouse inner hair cells. J. Physiol. 563:177-191

Khimich, D., Nouvian, R., Pujol, R., Tom Dieck, S., Egner, A., Gundelfinger, E.D., Moser, T. 2005. Hair cell synaptic ribbons are essential for synchronous auditory signalling. Nature 434:889-894

Klyachko, V.A., Jackson, M.B. 2002. Capacitance steps and fusion pores of small and large-dense-core vesicles in nerve terminals. Nature 418:89-92

Koschak, A., Reimer, D., Huber, I., Grabner, M., Glossmann, H., Engel, J., Striessnig, J. 2001. alpha 1D (Cav1.3) subunits can 
form 1-type $\mathrm{Ca}^{2+}$ channels activating at negative voltages J. Biol. Chem. 276:22100-22106

Koutalos, Y., Yau, K.W. 1996. Regulation of sensitivity in vertebrate rod photoreceptors by calcium. Trends Neurosci. 19:7381

Lenzi, D., Crum, J., Ellisman, M.H., Roberts, W.M. 2002. Depolarization redistributes synaptic membrane and creates a gradient of vesicles on the synaptic body at a ribbon synapse. Neuron 36:649-659

Lenzi, D., Runyeon, J.W., Crum, J., Ellisman, M.H., Roberts, W.M. 1999. Synaptic vesicle populations in saccular hair cells reconstructed by electron tomography. J. Neurosci. 19:119-132

Liberman, M.C. 1980. Morphological differences among radial afferent fibers in the cat cochlea: an electron-microscopic study of serial sections. Hear. Res. 3:45-63

Liberman, M.C. 1982. Single-neuron labeling in the cat auditory nerve. Science 216:1239-1241

Liberman, M.C., Dodds, L.W., Pierce, S. 1990. Afferent and efferent innervation of the cat cochlea: quantitative analysis with light and electron microscopy [published erratum appears in J. Comp. Neurol. 1991 Feb 8;304(2):341]. J. Comp. Neurol 301:443-460

Liley, A.W., North, K.A.K. 1953. An electrical investigation of effects of repetitive stimulation on mammalian neuromuscular junction. J. Neurophysiol. 16:509-527

Mansergh, F., Orton, N.C., Vessey, J.P., Lalonde, M.R., Stell, W.K., Tremblay, F., Barnes, S., Rancourt, D.E., Bech-Hansen, N.T. 2005. Mutation of the calcium channel gene Cacnalf disrupts calcium signaling, synaptic transmission and cellular organization in mouse retina. Hum. Mol. Genet. 14:3035-3046

Martinez-Dunst, C., Michaels, R.L., Fuchs, P.A. 1997. Release sites and calcium channels in hair cells of the chick's cochlea. J. Neurosci. 17:9133-9144

Matsubara, A., Laake, J.H., Davanger, S., Usami, S., Ottersen, O.P. 1996. Organization of AMPA receptor subunits at a glutamate synapse: a quantitative immunogold analysis of hair cell synapses in the rat organ of Corti. J. Neurosci. 16:4457-4467

Mennerick, S., Matthews, G. 1996. Ultrafast exocytosis elicited by calcium current in synaptic terminals of retinal bipolar neurons. Neuron 17:1241-1249

Merchan-Perez, A., Liberman, M.C. 1996. Ultrastructural differences among afferent synapses on cochlear hair cells: correlations with spontaneous discharge rate. J. Comp. Neurol. 371:208-221

Moser, T., Beutner, D. 2000. Kinetics of exocytosis and endocytosis at the cochlear inner hair cell afferent synapse of the mouse. Proc. Natl. Acad. Sci. USA 97:883-888

Neher, E. 1998. Vesicle pools and $\mathrm{Ca}^{2+}$ microdomains: new tools for understanding their roles in neurotransmitter release. Neuron 20:389-399

Neves, G., Lagnado, L. 1999. The kinetics of exocytosis and endocytosis in the synaptic terminal of goldfish retinal bipolar cells. J. Physiol. 515:181-202

Parsons, T.D., Lenzi, D., Almers, W., Roberts, W.M. 1994. Calcium-triggered exocytosis and endocytosis in an isolated presynaptic cell: capacitance measurements in saccular hair cells. Neuron 13:875-883

Parsons, T.D., Sterling, P. 2003. Synaptic ribbon. Conveyor belt or safety belt?. Neuron $\mathbf{3 7 : 3 7 9 - 3 8 2}$

Platzer, J., Engel, J., Schrott-Fischer, A., Stephan, K., Bova, S., Chen, H., Zheng, H., Striessnig, J. 2000. Congenital deafness and sinoatrial node dysfunction in mice lacking class D L-type $\mathrm{Ca}^{2+}$ channels. Cell 102:89-97

Rebillard, G., Ruel, J., Nouvian, R., Saleh, H., Pujol, R., Dehnes, Y., Raymond, J., Puel, J.L., Devau, G. 2003. Glutamate transporters in the guinea-pig cochlea: partial mRNA sequences, cellular expression and functional implications. Eur. J. Neurosci. 17:8392

Roberts, W.M. 1993. Spatial calcium buffering in saccular hair cells. Nature 363:74-76

Roberts, W.M. 1994. Localization of calcium signals by a mobile calcium buffer in frog saccular hair cells. J. Neurosci. 14:32463262

Roberts, W.M., Jacobs, R.A., Hudspeth, A.J. 1990. Colocalization of ion channels involved in frequency selectivity and synaptic transmission at presynaptic active zones of hair cells. J. Neurosci. 10:3664-3684

Rodriguez-Contreras, A., Yamoah, E.N. 2001. Direct measurement of single-channel $\mathrm{Ca}^{2+}$ currents in bullfrog hair cells reveals two distinct channel subtypes. J. Physiol. 534:669-689

Rutherford, M.A., Roberts, W.M. 2006. Frequency selectivity of synaptic exocytosis in frog saccular hair cells. Proc. Natl. Acad. Sci. USA 103:2898-2903

Russell, I.J., Sellick, P.M. 1978. Intracellular studies of hair cells in the mammalian cochlea. J. Physiol. 284:261-290

Safieddine, S., Wenthold, R.J. 1999. SNARE complex at the ribbon synapses of cochlear hair cells: analysis of synaptic vesicleand synaptic membrane-associated proteins. Eur. J. Neurosci. 11:803-812

Sakaba, T., Stein, A., Jahn, R., Neher, E. 2005. Distinct kinetic changes in neurotransmitter release after SNARE protein cleavage. Science 309:491-494

Schmitz, F., Konigstorfer, A., Sudhof, T.C. 2000. RIBEYE, a component of synaptic ribbons: a protein's journey through evolution provides insight into synaptic ribbon function. $\mathrm{Neu}$ ron 28:857-872

Schmitz, F., Tabares, L., Khimich, D., Strenzke, N., de la villaPolo, P., Castellano-Munoz., M., Bulankina, A., Moser, T., Fernandez-Chacon, R., Sudhof., T.C. 2006. CSP $\alpha$-deficiency causes massive and rapid photoreceptor degeneration. Proc. Natl. Acad. Sci. USA 103:2926-2931

Schnee, M.E., Lawton, D.M., Furness, D.N., Benke, T.A., Ricci, A.J. 2005. Auditory hair cell-afferent fiber synapses are specialized to operate at their best frequencies. Neuron 47:243254

Shnerson, A., Devigne, C., Pujol, R. 1981. Age-related changes in the C57BL/6J mouse cochlea. II. Ultrastructural findings. Brain Res. 254:77-88

Sidi, S., Busch-Nentwich, E., Friedrich, R., Schoenberger, U., Nicolson, T. 2004. gemini encodes a zebrafish L-type calcium channel that localizes at sensory hair cell ribbon synapses. J. Neurosci. 24:4213-4223

Slepecky, N.B., Galsky, M.D., Swartzentruber-Martin, H., Savage, J. 2000. Study of afferent nerve terminals and fibers in the gerbil cochlea: distribution by size. Hear. Res. 144:124-134

Sneary, M.G. 1988. Auditory receptor of the red-eared turtle: II. Afferent and efferent synapses and innervation patterns. J. Comp. Neurol. 276:588-606

Sobkowicz, H.M., Rose, J.E., Scott, G.E., Slapnick, S.M. 1982. Ribbon synapses in the developing intact and cultured organ of Corti in the mouse. J. Neurosci. 2:942-957

Spassova, M.A., Avissar, M., Furman, A.C., Crumling, M.A., Saunders, J.C., Parsons, T.D. 2004. Evidence that rapid vesicle replenishment of the synaptic ribbon mediates recovery from short-term adaptation at the hair cell afferent synapse. J. Assoc. Res. Otolaryngol. 5:376-390

Strom, T.M., Nyakatura, G., Apfelstedt-Sylla, E., Hellebrand, H., Lorenz, B., Weber, B.H., Wutz, K., Gutwillinger, N., Ruther, K., Drescher, B., Sauer, C., Zrenner, E., Meitinger, T., Rosenthal, A., Meindl, A. 1998. An L-type calcium-channel gene mutated in incomplete X-linked congenital stationary night blindness. Nat. Genet. 19:260-263 
Sudhof, T.C. 2004. The synaptic vesicle cycle. Annu. Rev. Neurosci. 27:509-547

Sun, J.Y., Wu, X.S., Wu, L.G. 2002. Single and multiple vesicle fusion induce different rates of endocytosis at a central synapse. Nature 417:555-559

tom Dieck, S., Altrock, W.D., Kessels, M.M., Qualmann, B., Regus, H., Brauner, D., Fejtova, A., Bracko, O., Gundelfinger, E.D., Brandstatter, J.H. 2005. Molecular dissection of the photoreceptor ribbon synapse: physical interaction of Bassoon and RIBEYE is essential for the assembly of the ribbon complex. J. Cell Biol. 168:825-836

Tucker, T., Fettiplace, R. 1995. Confocal imaging of calcium microdomains and calcium extrusion in turtle hair cells. Neuron 15:1323-1335

Tucker, T.R., Fettiplace, R. 1996. Monitoring calcium in turtle hair cells with a calcium-activated potassium channel. J. Physiol. 494:613-626

Valente, C., Spano, S., Luini, A., Corda, D. 2005. Purification and functional properties of the membrane fissioning protein CtBP3/BARS. Methods Enzymol. 404:296-316

Virmani, T., Han, W., Liu, X., Sudhof, T.C., Kavalali, E.T. 2003. Synaptotagmin 7 splice variants differentially regulate synaptic vesicle recycling. EMBO J. 22:5347-5357 von Gersdorff, H., Matthews, G. 1994. Dynamics of synaptic vesicle fusion and membrane retrieval in synaptic terminals. Nature 367:735-739

von Gersdorff, H., Vardi, E., Matthews, G., Sterling, P. 1996. Evidence that vesicles on the synaptic ribbon of retinal bipolar neurons can be rapidly released. Neuron 16:12211227

Westerman, L.A., Smith, R.L. 1984. Rapid and short-term adaptation in auditory nerve responses. Hear. Res. 15:249-260

Xu, T., Binz, T., Niemann, H., Neher, E. 1998. Multiple kinetic components of exocytosis distinguished by neurotoxin sensitivity. Nat. Neurosci. 1:192-200

Yates, G.K., Robertson, D., Johnstone, B.M. 1985. Very rapid adaptation in the guinea pig auditory nerve. Hear. Res. 17:1-12

Zenisek, D., Davila, V., Wan, L., Almers, W. 2003. Imaging calcium entry sites and ribbon structures in two presynaptic cells. J. Neurosci. 23:2538-2548

Zenisek, D., Horst, N.K., Merrifield, C., Sterling, P., Matthews, G. 2004. Visualizing synaptic ribbons in the living cell. J. Neurosci. 24:9752-9759

Zenisek, D., Steyer, J.A., Almers, W. 2000. Transport, capture and exocytosis of single synaptic vesicles at active zones. Nature 406:849-854 